\title{
Anatomical Variations in the lobes and fissures of the lungs
}

\section{Case report}

\section{Alka Jayavanth Kumar ${ }^{1^{*}}$}

1. Professor \& HOD Dept of Shareera Rachana, JSS Ayurveda Medical College Mysore - 28

\begin{abstract}
Generally Right lung contains two fissures [oblique and horizontal] and three lobes [upper, middle and lower].Left lung contains one oblique fissure and two lobes [upper and lower].Sometimes the number of lobes may vary in either lung. The right lung may have only two lobes upper and lower and the left lung may have three lobes. In rare cases Accessory fissures and extra lobes may present. This type of variations is occurred in the cases of developmental anomalies of lungs. During dissection of a cadaver of 60 years old male, we found variations in the lungs. The present case report an unusual Inferior Accessory Fissure in the lower lobe of the Right lung as well as an extra lobe in the Right lung. The Left lung contain an incomplete small fissure as well as extra incomplete lobe. The measurement of extra fissure had been taken and will be displayed with detailed information and photographs.
\end{abstract}

Key Words: Lungs, Lobes, Fissures, Accessory, Variations

\section{Introduction}

Lungs are one of the vital organs of human body. In the anatomical view normally right lung contains two fissures (Oblique and Horizontal) and three lobes (Upper, Middle and Lower) Left lung contains one oblique fissure and two lobes (Upper and Lower). Normally lingula is present in left lung and not in right lung.

The knowledge of anatomical variations of the lobes of the lungs is important for identifying bronchopulmanary segments. Anatomical knowledge of such variations is helpful for loboctomies and surgical resections involving individual segments.

\footnotetext{
*Corresponding Author:

Alka Jayavanth Kumar, Professor \& HOD

Dept of Shareera Rachana, JSS Ayurveda Medical College, Mysore - 28

E-mail id: dralkajk@gmail.com
}

\section{Case Report-}

During routine dissection of thoracic region of 60 years old male cadaver, we encountered anomalies in the lungs, which displayed variation in the pattern of fissures and lobes. The pulmonary fissures and lobes were studied and appropriate measurements, were taken. The specimen has photographed

\section{Specific variations:}

Right Lung: Picture-1 and Picture-2

Oblique fissure - Length $14 \mathrm{cms}$.It crossed the posterior border at a distance $9 \mathrm{~cm}$ from apex cut anterior border at a distance $6 \mathrm{cms}$ from the upper end of a anterior border [generally oblique fissure cut the inferior border and not the anterior border]. Anterior border - length $10 \mathrm{~cm}$. Oblique fissure - length $14 \mathrm{~cm}$. 
Horizontal fissure - It started from the midpoint of oblique fissure and cut the posterior border at $14 \mathrm{~cm}$ distance from the apex of lung on the posterior border length $-7.5 \mathrm{cms}$.

Inferior Accessory Fissure pic 2 It was present in the lower lobe. It started from inferior border $3 \mathrm{cms}$ from midline, ran obliquely upwards and cut the oblique fissure at its midpoint i.e. $8.5 \mathrm{~cm}$ from midline. At these point 3 fissures - oblique, horizontal and inferior accessory met together. Length of inferior accessory fissure is $9 \mathrm{cms}$. Due to this fissure the lower lobe has been divided into one small extra lobe and a large lower lobe

Left lung: Picture - 4

One small incomplete horizontal fissure starts from anterior border at the junction of upper $1 / 3$ and middle $2 / 3$ and runs some $7 \mathrm{cms}$ distance and ends on the lungs tissue. It makes one other extra incomplete lobe.

Lingula comes out from the anterior end of oblique fissure

Weight of Right lung $-570 \mathrm{gm}$.

Weight of Left lung - 365gm.

\section{Discussions}

The defective pulmonary development gives rise to variations in lobes and fissures of lungs. The fissures are the spaces which separate individual broncho- pulmonary buds on segments and they got obliterated except along the two planes which later manifests as horizontal or oblique fissure. Non obliteration of these spaces gives rise to accessory fissures of the lung. An accessory fissure may be varying depth occurring between bronchopulmonary segments (David and Tarver 1984). Accessory fissures may be present in any of the five lobes. The Inferior accessory fissure is the most common fissure detected on CT scans (David and Tarver).

\section{Conclusion}

In the present study the accessory fissure detected on the right lung can be correctly termed as inferior accessory fissure.

\section{References:}

1. J.D. Godwin and R.D Tarver Accessory fissures of the lung (1985)

2. M. David.J. Frija - Incomplete and accessory pulmonary fissures studied by high resolution CT scan (1988)

3. A. Aziz.N. Nagaoki- High resoluation C.T. anatomy of pulmonary fissures (2004)

4. R.S. Fraser, N.L. Muller- Diagnostic diseases of the chest (1999) 


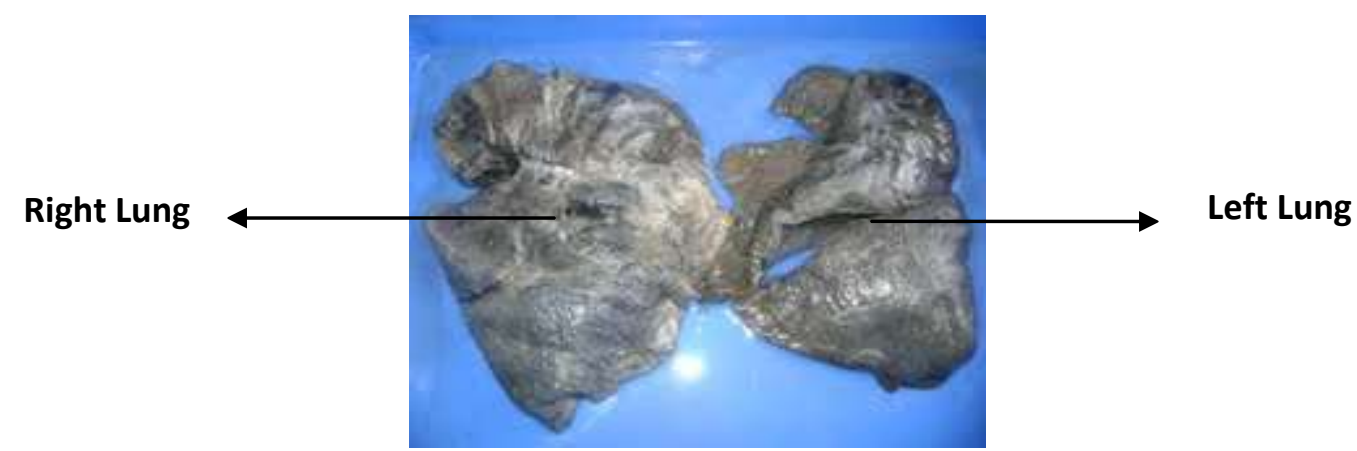

Fig 1 Lungs

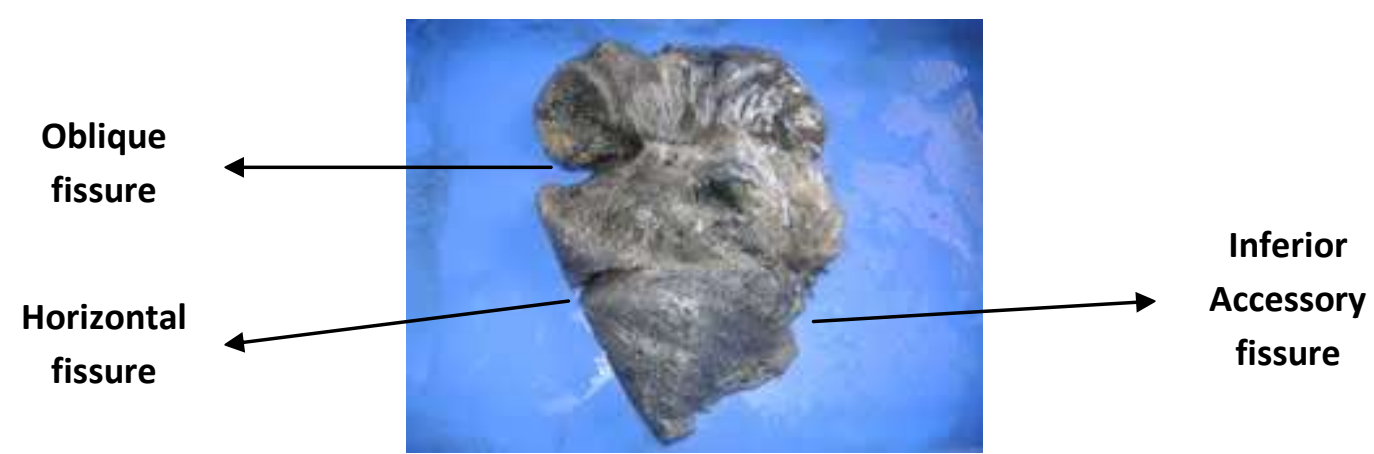

Fig 2 Fissures of Right Lung

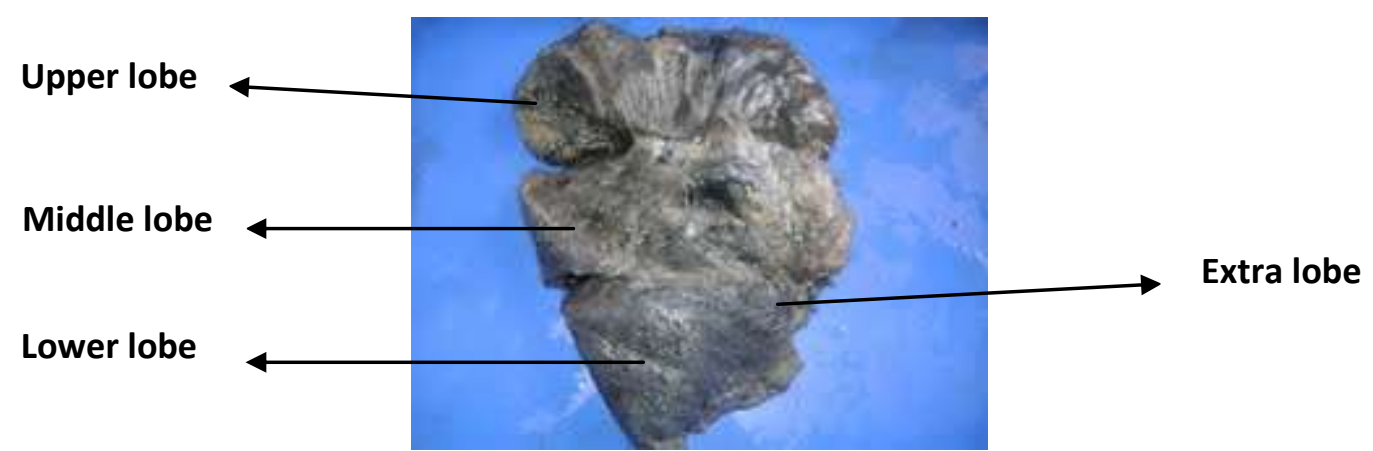

Fig 3 Lobes of right lung

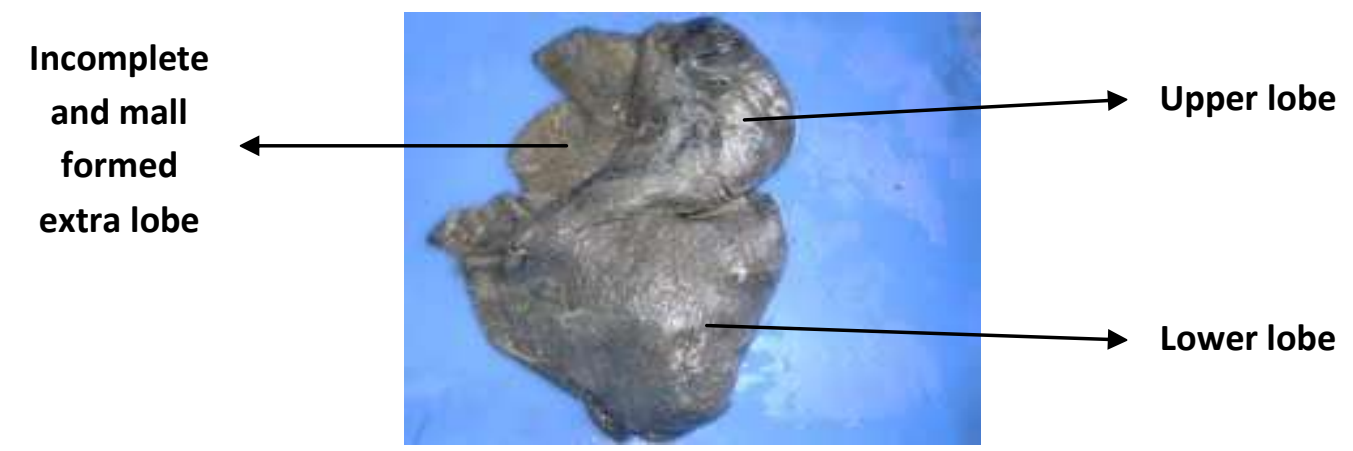

Fig 4 Lobes of left lung 